\title{
REPENSANDO A AVALIAÇÃO: PERSPECTIVAS CRIATIVAS PARA A EDUCAÇÃO PROFISSIONAL NA ÁREA DA SAÚDE DO TRABALHADOR
}

\author{
RETHINKING THE EVALUATION: CREATIVE PERSPECTIVES FOR THE PROFESSIONAL EDUCATION \\ IN THE WORKER'S HEALTH AREA
}

Marilda Moreira ${ }^{1}$

Resumo Este trabalho propõe a discussão de formas alternativas às provas e aos testes na avaliação escolar. Sendo assim, foram apresentadas duas experiências realizadas com alunos do Curso Técnico de Vigilância Sanitária e Saúde Ambiental, da Escola Politécnica de Saúde Joaquim Venâncio, unidade da Fundação Oswaldo Cruz, que visavam à ruptura com o modelo tradicional de avaliação, marcado pela relação verticalizada entre professor e aluno no processo de ensinoaprendizagem. Argumenta-se que, dependendo da forma como é conduzida, a avaliação pode ser um instrumento autoritário, punitivo e estigmatizante e, nesse sentido, cabe aos profissionais da área de educação uma reflexão sobre seu posicionamento ideológico e político, a fim de perceberem se sua prática docente estaria contribuindo para a manutenção das desigualdades sociais.

Palavras-chave avaliação; ensino-aprendizagem; educação profissional; saúde do trabalhador.
Abstract This work proposes the discussion of alternative forms to the exams and the texts in school evaluation. Thus, two experiences were presented, performed with students from the Technical Course of Sanitary Vigilance and Environmental Health, the Joaquim Venâncio Polytechnic School of Health, Fundação Oswaldo Cruz unit, which sought to break with the traditional model of evaluation, marked by the verticalized relationship between teacher and pupil in the teaching-learning process. It is argued that, depending on the way it is conducted, the evaluation can be an authoritarian, punitive and stigmatizing instrument and, in this sense, it is up to the professionals from the education area a reflection on its ideological and political positioning, so as to perceive if its teaching practice would be contributing to the maintenance of social unequalness.

Key words evaluation; teaching-learning; professional education, worker's health. 


\begin{abstract}
"No descomeço era o verbo.
Só depois é que veio o delírio do verbo.

O delírio do verbo estava no descomeço, lá onde a criança diz: Eu escuto a cor dos passarinhos. A criança não sabe que o verbo escutar não funciona para cor, mas para som. Então se a criança muda a função de um verbo, ele delira. E pois. Em poesia que é a voz do poeta, que é a voz de fazer nascimentos O verbo tem que pegar delírio."
\end{abstract}

(Manoel de Barros, O livro das ignorãças)

\title{
Sobre o contexto
}

A experiência relatada neste artigo ocorreu no primeiro semestre de 2004, na Escola Politécnica de Saúde Joaquim Venâncio, unidade da Fundação Oswaldo Cruz (EPSJV/Fiocruz). Constituiu-se a partir das práticas docentes desenvolvidas no Laboratório de Educação Profissional em Vigilância em Saúde (Lavsa), que oferece diversos cursos, dentre eles o Técnico de Vigilância Sanitária e Saúde Ambiental.

Este curso é constituído por cinco módulos que duram em geral um semestre. Um desses módulos é o de Vigilância em Saúde do Trabalhador², composto por seis eixos temáticos de discussão, com carga horária de 300 horas.

A questão inicial com a qual nos deparamos foi o grande número de adolescentes que têm ingressado nesta escola, via concurso público, nos últimos anos, em busca de uma especialização técnica, fato este que faz com que o perfil dos discentes seja composto majoritariamente por jovens que ainda não ingressaram no mercado de trabalho. Em parte, isto se deu pela dificuldade que muitos trabalhadores têm de conciliar seu horário de trabalho (por vezes composto por jornadas duplas ou triplas) com o horário vespertino das aulas. Ora, este fato surgiu como um problema, no sentido de que suscitou inúmeros desafios, pois é delicado tratar de uma temática demasiada densa, como a saúde do trabalhador - que retrata a dolorosa realidade da exploração, das morbidades e mortalidades relacionadas aos processos de trabalho -, para adolescentes que estão no ápice de vida, em meio à alegria, tentando entender as suas contradições e buscando a construção da sua identidade pessoal e profissional. 
Com o desenrolar do módulo, surgiram outras questões: como desenvolver as avaliações destes alunos ao longo do módulo? Que propostas poderiam ser feitas? Como avaliar esses conteúdos densos sem a angustiante sensação que as provas causam? Como as avaliações poderiam se constituir como formas propiciadoras da reflexão e da crítica.

Felizmente, muitos profissionais que atuam no vasto campo da educação concordam que se devem utilizar os mais diversos recursos didáticos como fonte de estímulo à construção do conhecimento com os discentes. Contudo, muitas vezes há um hiato entre a proposta dinâmica das aulas e a avaliação da aprendizagem, prioritariamente marcada pelo 'teste' e pela 'prova'.

Dependendo do modo como é conduzida, a avaliação pode inibir toda a criatividade suscitada nos alunos durante as aulas, assim como o discurso da formação cidadã para o desenvolvimento de pessoas plenas fica esvaziado de um sentido prático, pois o processo de construção de um conhecimento democrático passa a ser válido somente até determinado ponto e, com freqüência, a 'nota' torna-se a medida fundamental e classificadora do aluno 'bom', 'regular' ou 'ruim'.

\section{Por uma avaliação crítica e reflexiva}

O Curso Técnico de Vigilância Sanitária e Saúde Ambiental há alguns anos tem como proposta a elaboração de uma monografia ou texto científico ao final de cada módulo3. Os alunos contam com a colaboração de orientadores do Lavsa, dos demais laboratórios da Escola Politécnica, bem como de pesquisadores de outras unidades da Fiocruz. Esta proposta tem sido desenvolvida de forma bastante positiva, visto que proporciona ao aluno o contato com campos de investigação até então desconhecidos, e também com a iniciação científica. Então, de certa forma, a avaliação estava em parte configurada, porém a pergunta era se a monografia, por si só, deveria ser o único parâmetro avaliativo do aluno no módulo de Saúde do Trabalhador.

A coordenação do módulo pensou então que seria interessante fazer várias avaliações dos alunos em cada eixo temático, para que os esforços não ficassem todos focalizados na monografia. Nosso grupo de trabalho concordou que, em virtude do meu interesse particular na incorporação de novas metodologias ao processo ensino-aprendizagem, em especial as ligadas à arte, poderia ser a profissional responsável pela elaboração e condução das avaliações enfocadas neste relato.

Tendo em vista estas considerações, novamente surgiram outras perguntas, inspiradas pela visão crítica de Luckesi (2003) sobre o tema. Qual avaliação? Que modelo utilizar? A avaliação faz jus às possibilidades de 
desenvolvimento do aluno? Avaliar para quê? Avaliar para quem? Esta avaliação serviria para medição do conhecimento acumulado, apreendido?

Ao marcar a data da primeira avaliação, surgiram na turma as perguntas clássicas: teremos prova? Será um teste? Teremos trabalho em grupo? Faremos trabalhos individuais?

Diante destas questões, pensamos ser interessante focar um primeiro ponto: paremos para pensar no significado das palavras 'prova' e 'teste'. A tradição do nosso ensino ressalta que o aluno deve 'provar' que sabe ao professor. Seus conhecimentos devem ser 'testados' pelo professor, que julgará se a sua "visão social de mundo" (Löwy, 1991), ou seja, se suas idéias, crenças, valores, representações e orientações cognitivas, é 'adequada' ao conhecimento que o professor transmitiu. Muitas vezes, a visão social de mundo do aluno é vista pelo professor como 'oposta' à sua. Assim, com o poder que é atribuído a este último, caberia julgá-la como 'errada' ou 'ruim'.

De imediato, percebemos que o processo de avaliação que se perpetua em nossa sociedade retrata uma relação verticalizada de ensino-aprendizagem, em que o aluno prova o que sabe respondendo aquilo que o professor estipula como essencial. Se este essencial, predefinido de forma não dialógica, estiver cem por cento de acordo com o que o professor definiu, o aluno terá nota máxima. Isto sem mencionar o fato de que muitas vezes a avaliação é utilizada de forma autoritária. Conforme aponta Moretto,

“A avaliação da aprendizagem é angustiante para muitos professores por não saberem como transformá-la num processo que não seja uma mera cobrança de conteúdos aprendidos 'de cor', de forma mecânica e sem muito significado para o aluno. Angústia por ter que usar um recurso tão valioso no processo educativo, como recurso de repressão, como meio de garantir que uma aula seja levada a termo com certo grau de interesse. Sentenças como 'anotem, pois vai cair na prova', 'prestem atenção nesse assunto porque na semana que vem tem prova', 'se não ficarem calados vou fazer uma prova surpresa', 'já que vocês não param de falar, considero a matéria dada e vai cair na prova', e outras que se equivalem, são indicadores da maneira repressiva [como] tem sido utilizada a avaliação da aprendizagem" (Moretto, 2004, p. 93, grifo do autor).

O mesmo autor acrescenta: “a avaliação da aprendizagem é um momento privilegiado de estudo e não um acerto de contas" (Moretto, 2004, p. 96).

Entendemos que esta visão repressora da avaliação não contribui para o aprendizado do aluno e ainda impede que o mesmo tenha uma vinculação afetiva positiva com o conhecimento. E mais: a avaliação pode ser um momento privilegiado de reflexão e crítica aos conteúdos trabalhados nas aulas. De igual modo, em nossa experiência queríamos propor uma avaliação democrática contrapondo-se às avaliações tradicionais, autoritárias, que 
exigem a submissão do aluno ao conteúdo trabalhado pelo professor em sala de aula, que não permitem a construção do conhecimento, mas apenas testam conhecimentos, conforme aponta Luckesi (2003).

Tentamos estipular formas transgressoras deste modelo repressor, utilizando vários modos de expressão, como a arte, a música, a dramatização, os recursos pictóricos, o trabalho com argila, a prosa e a poesia, como elementos facilitadores da criação.

Em relação à criação, é interessante explorar o pensamento de Cuéllar, que nos diz que

“Hoje, mais do que nunca, é necessário cultivar a criatividade humana, pois, em um contexto de rápida mutação, os indivíduos, as comunidades e as sociedades só podem adaptar-se ao que é novo e transformar sua realidade por meio da iniciativa e da imaginação criadoras. A noção de criatividade deve ser amplamente utilizada, não apenas para se referir à produção de novas obras ou formas artísticas, mas para buscar soluções de problemas em todas as áreas possíveis. Longe de ser exclusivamente ligada às artes, a criatividade é vital para a indústria e o comércio, a educação e o desenvolvimento social e comunitário" (Cuéllar, 1997, p. 101-102).

Desse modo, segundo o autor, a criatividade deve ser desenvolvida, nutrida e cuidada, pois não é matéria que pode ser ensinada ou encomendada.

\section{Avaliação e Criação}

Tendo em vista esta concepção sobre a criatividade, segue o relato de duas ${ }^{4}$ experiências ocorridas na sala de aula, das quais houve um retorno bastante positivo por parte dos discentes, assim como da coordenação.

Na primeira avaliação do grupo, formado por 18 alunos, seguiu-se a tensão clássica, permeada pelo medo do que iria 'cair' na prova, se teriam boas ou más notas. Isso trouxe nosso primeiro desafio, qual seja o de desconstruir com os alunos a concepção punitiva da avaliação, haja vista que para eles ainda havia a impressão de que seria efetuada a 'medição' de seus conhecimentos, pois esta foi a forma como transcorreram quase todas as avaliações realizadas durante sua vida acadêmica.

Inicialmente, foi distribuído à turma um artigo de revista que tratava da situação de um trabalhador que tentou se suicidar no Congresso Nacional, em virtude do desespero ante sua pobreza. Todos leram. Seguiu-se um silêncio abissal. Logo em seguida, foi distribuído outro texto, de Leonardo 
Boff (2002), sobre a metáfora da condição humana, constante em seu livro A águia e a galinha. Novamente, o silêncio se seguiu. Em seqüência, cada aluno recebeu uma folha de papel em branco. Pedimos que tentassem estabelecer uma conexão entre os dois textos, escritos em linguagens distintas (a jornalística e a literária) e o conteúdo do eixo temático sobre processo de trabalho. Com isto, tínhamos como objetivo estimular a reflexão sobre o trabalho em nossa sociedade capitalista. Ainda silêncio. Foi então que ocorreu a transformação: sobre uma mesa, no centro da sala, foram colocadas inúmeras canetas, tintas, pincéis, lápis de cor, lápis de cera, cola colorida, lantejoulas fitas, etc. Pediu-se aos alunos que se expressassem plasticamente e que, desta forma, usando a criatividade, fizessem a conexão entre os textos lidos e a saúde do trabalhador. Em poucas palavras, podemos resumir o espírito que se instaurou na turma: alívio, alegria, descontração da couraça tensa que tomava conta de seus corpos antes da avaliação.

Naquele momento a avaliação deixou de ser vista como um conceito fechado, de medição burocrática do conhecimento ao qual se atribui um valor numérico. Passou a ser propiciadora de momentos de criação, de reflexão, de fixação do conhecimento e de prazer.

A tensão estabelecida pelo clima de 'o que eu vou escrever na prova' cedeu lugar à imaginação criativa - dimensão sufocada cotidianamente pela realidade que nos requisita e exige registros oficiais, padronizados por uma linguagem que quer se impor como única via para a manutenção da 'seriedade' escolar.

O que vimos nesta primeira avaliação foi que o tom dramático, causado pela aplicação de uma prova, cedeu lugar à profusão de cores, formas, imagens, explosão de conhecimentos sentidos que não poderiam ser expressos de melhor forma. Afinal, a imagem de uma águia pousada sob o túmulo da CLT (Consolidação das Leis Trabalhistas), conforme a leitura plástica de um de nossos alunos, não expressa muito mais do que duas folhas de papel almaço escritas dos dois lados? 


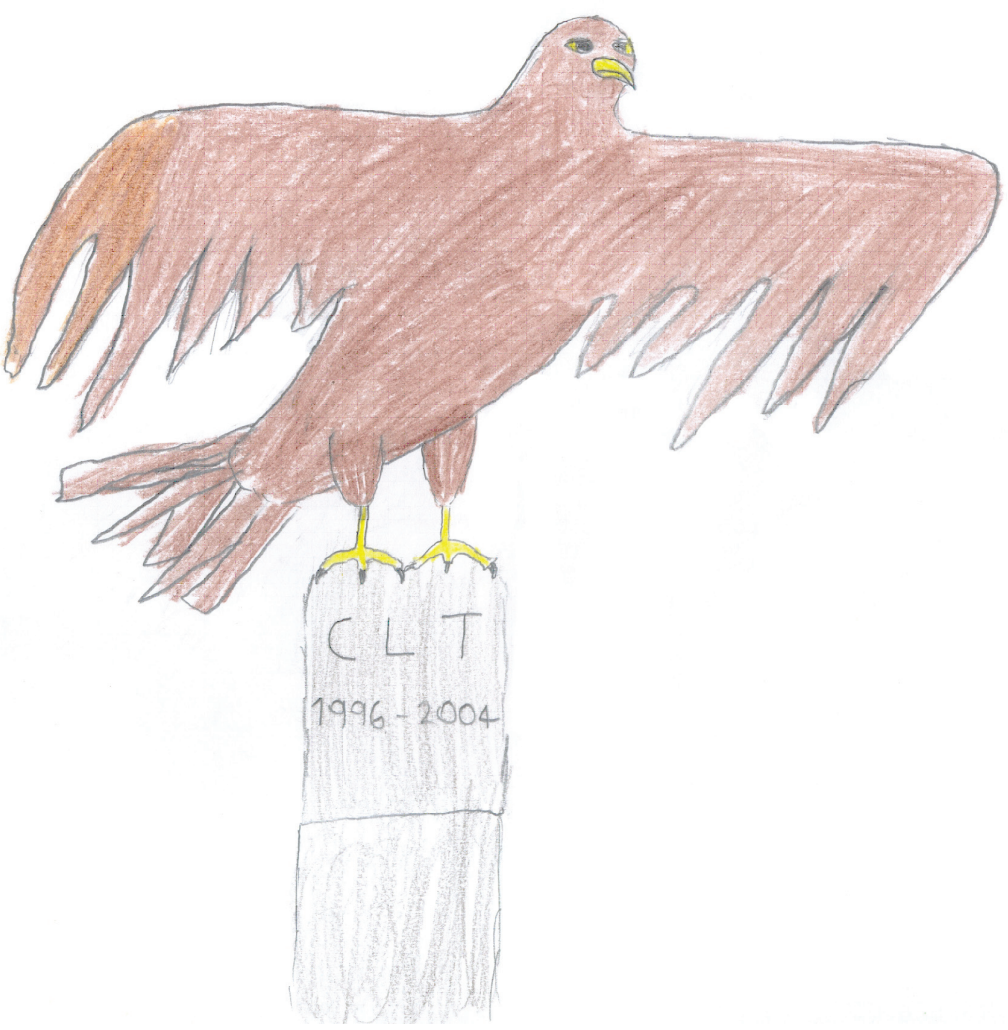

Fonte: Desenhos elaborados por alunos do Curso Técnico de Vigilância Sanitária e Saúde Ambiental, da Escola Politécnica de Saúde Joaquim Venâncio.

E o que dizer sobre o trabalhador sobre o trabalhador, desenhado por uma das nossas alunas, sem orelhas, com a fala, a visão e o pensamento interditados pelo taylorismo/fordismo? Isto não retrata a realidade vivida por milhões de pessoas no mundo do trabalho? 


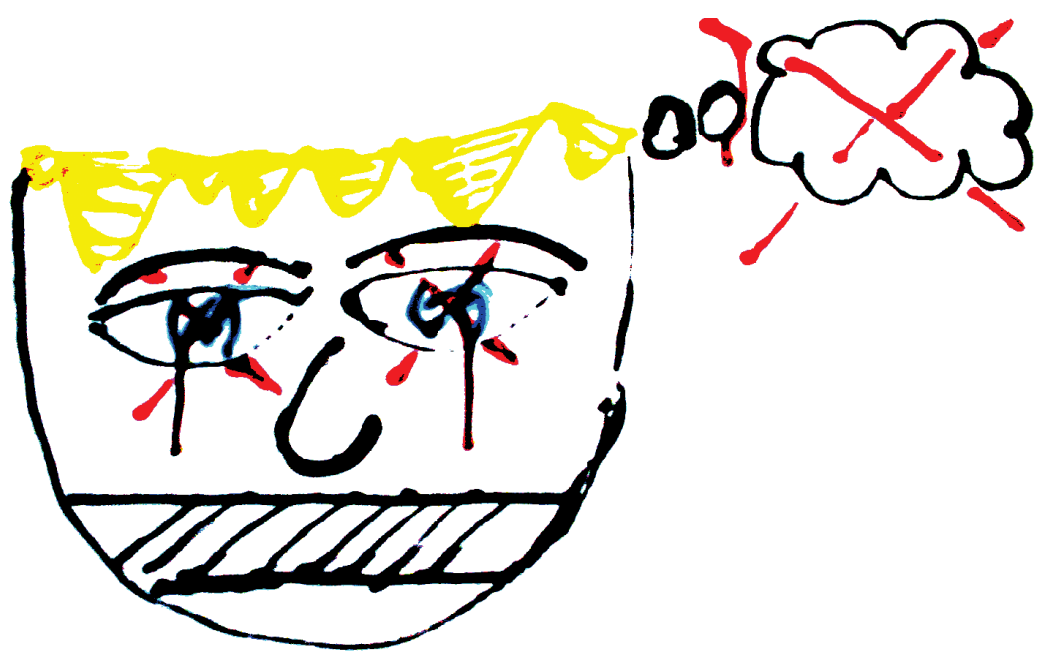

Fonte: Desenhos elaborados por alunos do Curso Técnico de Vigilância Sanitária e Saúde Ambiental, da Escola Politécnica de Saúde Joaquim Venâncio

Assim como estas, surgiram muitas outras imagens reveladoras: inúmeros horizontes, rostos com dor, a pobreza e a riqueza retratadas. Tudo expresso por imagens que dizem muito e que também revelam conteúdos nem sempre conscientes.

Depois da elaboração, as imagens foram apresentadas e discutidas pelos alunos, que destacaram o que mais lhes chamara a atenção em cada uma. Acreditamos que, para potencializar a avaliação como dispositivo de aprendizagem, seria ainda importante poder partilhar, em grupo, as diferentes reflexões que os alunos buscaram expressar com os desenhos. A discussão em grupo pode contribuir também para o desvelamento de conteúdos simbólicos nem sempre conscientes. Não raro, nos deparamos com falas como: 'não sei porque fiz esse desenho' e, instantes depois, o próprio aluno sugeria as possíveis conexões entre a imagem que criou e os conteúdos das aulas. Entendemos que esse momento se configurou como um saber marcante não só para o momento da avaliação, mas também para a construção da sua identidade profissional, em que as possibilidades de criação e do vislumbre de formas alternativas do conhecimento se deram.

Outra avaliação proposta a esses alunos foi a de que encenassem personagens na montagem de um tribunal, com magistrados, réu, testemunhas 
e advogados. A questão selecionada foi a problemática do amianto/asbesto, causador da asbestose - doença que ocasiona problemas respiratórios graves e neoplasias pulmonares. O tema havia sido abordado em aulas anteriores, incluindo a discussão de artigo científico e legislação pertinente. Existe uma grande dificuldade de se reconhecer esta doença como inerente ao processo de trabalho na indústria do amianto, visto que sua manifestação geralmente ocorre após uma década de exposição a esta matéria-prima, quando, em geral, os trabalhadores, após terem apresentado os primeiros sinais de diminuição da capacidade respiratória, já foram demitidos (D’Acri, 2003).

Esta segunda avaliação tinha, portanto, como escopo verificar o entendimento desta problemática pelos alunos, tentando também sensibilizá-los para a contundência do mundo do trabalho que, em suma, determinam a qualidade de vida da população e dos indivíduos.

O resultado, mais uma vez, foi bastante positivo: os alunos encenaram os aspectos sociais pertinentes à saúde do trabalhador, tais como as desigualdades de classes e as mudanças globais, que, como argumenta Giddens (2000), impõem a todos nós seus efeitos nos modos de vida, seja para o bem ou para o mal.

Talvez seja importante registrar que a dinâmica desta avaliação foi concebida prevendo a participação de todos os alunos, o que se efetivou na prática, contudo eles tinham a liberdade para escolherem seus grupos e construírem seus próprios papéis.

No exercício de encenação desta realidade, um grupo de alunos viveu a história de personagens que estavam doentes em virtude dos longos anos de trabalho em uma indústria de amianto e, por isso, lutavam na justiça por uma indenização. Do outro lado, outro grupo de alunos atuava em defesa da indústria do amianto: advogados que estavam prontamente dispostos a converter as vítimas em réus, médicos que tentavam minimizar as responsabilidades da indústria em relação à saúde dos trabalhadores, mostrando radiografias (desenhadas pelos alunos) que não condiziam com o suposto estado de saúde dos trabalhadores. Em contrapartida, os advogados de defesa apresentaram gráficos (também criado pelos alunos) para demonstrar os lucros da empresa e a possibilidade de investimento em tecnologias alternativas ao amianto. Enfim, temas absolutamente pertinentes à área da saúde do trabalhador.

Em suma, os alunos expuseram questões cruciais relacionadas à saúde dos trabalhadores expostos ao amianto, muito congruentes com o tema exposto nas aulas anteriores. Porém, as questões centrais apontadas foram colocadas com mais leveza através da dramatização, aliando o prazer de criar e de aprender. E o conhecimento transformado em uma dramatização, encarnado em personagens, pode dar margem ao pensamento sem a censura que uma prova ou um teste impõem. 
Alguns dias depois, a turma teve a possibilidade de participar de uma mesa redonda organizada pela coordenação do módulo com pesquisadores do Centro de Estudos da Saúde do Trabalhador e Ecologia Humana (Cesteh/ Fiocruz). Participaram também da mesa duas senhoras vítimas do amianto ${ }^{5}$. Certamente, naquele momento os alunos perceberam, de fato, que muitos dos assuntos tratados sob a forma de dramatização na avaliação eram problemas reais que atingiam a qualidade de vida dos trabalhadores e que dependiam de ações integradas, que demandavam um grande comprometimento ético e político. A avaliação, nesse momento, deixou também de ser pontual, com validade apenas para um determinado momento, conforme discute Luckesi (2003). A avaliação transcendeu não só o espaço da sala de aula, integrou conhecimentos e vivências de situações de saúde relacionadas ao tema proposto, mas também o tempo, aqui e agora, da avaliação do conhecimento do aluno.

Apesar destas propostas virem acompanhadas pelo desejo da liberdade de expressão dos alunos, em ambas as avaliações eles tiveram uma dificuldade inicial para decidir o que fazer, o que desenhar, o que representar. No primeiro caso, percebia-se a paralisação dos alunos durante alguns minutos ante a folha em branco e do inesperado. Seguiram-se a partir daí inúmeras justificativas e reclamações: "eu não sei desenhar", "não vou colocar o meu nome no desenho, não quero pagar mico", "isso está horrível". Frases esperadas, pois, em geral, reprimimos nossa criatividade e a possibilidade de criarmos imagens desde a infância ${ }^{6}$, em detrimento do que se considera apenas como esteticamente 'bom'. Entenda-se que esta construção do 'bom' para nós leigos nem sempre é a mesma do 'bom' para os expertos em arte, mas está muito mais ligado ao que é socialmente construído como 'bonito'.

Philippini destaca o quanto somos tolhidos em nossa criatividade, ao mencionar que:

“O lugar que habitualmente as artes plásticas têm no currículo escolar ratifica esta tendência. Até o Jardim de Infância é possível desenhar, pintar e modelar rotineiramente. A classe de alfabetização traz a ruptura. Chegam os cadernos, alguns até de caligrafia, lápis preto e borracha, régua, esferográficas e alguns livros. O lápis de cor até é permitido, mas agora, quase sempre só para pintar os exercícios dos livros ou as tarefas mimeografadas para serem feitas em casa. E, neste quadro, são poucas as escolas que oferecem exceções. Deste modo, começamos a enterrar junto com as experimentações expressivas e plásticas uma parte da ousadia e da espontaneidade, sufocando algumas das habilidades que decorrem do livre exercício de potencialidades criativas e que podem levar à comunicação mais ampla e flexível e a sentimentos de plenitude e inteireza" (Philippini, 2001, p. 65-66). 
Talvez a paralisação inicial dos alunos esteja vinculada ao fato de que desde cedo nos frustramos com a tentativa de transformar os sentimentos em imagens. Desta forma, somos treinados a nos expressar através da palavra (oral e escrita). Assim, para boa parte das pessoas que não consegue fazer desenhos 'bons', fecha-se uma porta de externalização do sentir.

Contudo, apesar desta dificuldade, o resultado final foi bastante gratificante para os alunos, principalmente por verem concluído um 'produto' da sua reflexão: uma 'forma', criada a partir daquilo que foi sentido e aprendido, transformado em símbolo, neste caso imagético. Estes símbolos nos acompanham, conforme analisa Henderson (2002), desde a pré-história, tornando-se representativos de nossas crenças, costumes e valores.

Para Jung,

“Uma palavra ou uma imagem é simbólica quando implica alguma coisa além do seu significado manifesto e imediato. Esta palavra ou esta imagem tem um aspecto 'inconsciente' mais amplo, que nunca é precisamente definido ou de todo explicado. (...) Quando a mente explora um símbolo, é conduzida a idéias que estão fora do alcance da nossa razão (...). Por existirem inúmeras coisas fora da compreensão humana é que freqüentemente utilizamos termos simbólicos como representação de conceitos que não podemos definir ou compreender integralmente" (Jung, 2002, p. 20-21).

Em meio a estas possibilidades de expressão, há uma outra perspectiva imbricada nas experiências citadas que foi também nosso objetivo: trata-se da abertura dos nossos alunos, protagonistas no processo de aprendizagem, para o mundo, através da abertura de si mesmos.

\section{Algumas questões ainda sem solução}

O esforço por construir uma avaliação que fuja aos moldes de provas e testes não indica, em absoluto, falta de comprometimento ou flexibilidade em relação à apreensão dos conteúdos7 . Faz-se necessário registrar que a opção por introduzir metodologias alternativas de avaliação não está ancorada no interesse de facilitar a aprovação dos alunos, no entanto reconhecemos que a ausência de avaliações 'tradicionais' implica, em muitos casos, que o aluno não estude. Os períodos de realização de provas e testes às vezes são os únicos momentos em que os alunos realmente sentam para ler os assuntos discutidos em sala de aula.

Contudo, Luckesi aponta algumas conseqüências da "pedagogia do exame que visa à atribuição de notas e à classificação dos alunos, fruto de uma prática antidemocrática e autoritária: 
“(...) pedagogicamente, ela centraliza a atenção nos exames; não auxilia a aprendizagem dos estudantes. A função verdadeira da avaliação da aprendizagem seria auxiliar a construção da aprendizagem satisfatória; porém, como ela está centralizada nas provas e exames, secundariza o significado do ensino e da aprendizagem como atividades significativas em si mesmas e superestima os exames. Ou seja, pedagogicamente, a avaliação da aprendizagem, na medida em que estiver polarizada pelos exames, não cumprirá a sua função de subsidiar a decisão da melhoria da aprendizagem" (Luckesi, 2003, p. 25, grifo do autor).

Um exemplo de como o estudo dos conteúdos tratados em sala de aula está condicionado às provas e testes pode ser resumido na breve conversa de uma aluna com um colega: "Fulano, eu estou fazendo avaliação". Indescritível foi a expressão de surpresa dele ao vê-la do lado de fora da sala de aula, no corredor, aguardando o momento em que iria entrar para fazer apresentação na cena do tribunal, que comentamos anteriormente. E a aluna completou: "a nossa avaliação é assim, não tem prova". Outra vez surpreso, ele prontamente perguntou: "Não tem prova? Então não tem que estudar?".

Infelizmente, sabemos que a cultura que se estabeleceu em relação à disciplina de estudo está ainda muito condicionada às provas e testes. Existe, efetivamente, em nossa sociedade um sistema educacional organizado por disciplinas que mede o desempenho dos alunos através de valores numéricos que tem suas raízes fincadas no século XVI, como aponta Luckesi (2003). Em meio a esta realidade nada animadora, vem também a certeza de que as mudanças somente ocorrem por meio do debate ampliado nos meios de formação discentes e docentes e de ações efetivamente inovadoras que primem pela emancipação do ser humano.

Neste sentido, a classificação taxativa do aluno 'bom' ou 'ruim', em uma ou mais disciplinas, também condicionará o seu status na sociedade e até sua possível profissão. Em outras palavras, o 'mau' desempenho do aluno em certas disciplinas faz com que o mesmo seja excluído da possibilidade de alguns estágios ou da participação em grupos de pesquisa voltados à iniciação científica, por exemplo. Esse julgamento valorativo pode impedir que o aluno aprenda a gostar de determinados conteúdos teóricos, pois ele não criou uma vinculação positiva com o conhecimento. As repetidas notas 'ruins' podem fazer com que o aluno pense que não tem capacidade de aprender e que, portanto, não lhe cabe optar por carreiras que exijam conhecimentos específicos em áreas em que sempre foi avaliado como 'fraco'.

Luckesi (2003) nos fornece mais subsídios à crítica do modelo vigente de avaliação que não permite um diagnóstico do processo de ensino-aprendizagem, mas que termina por estabelecer uma classificação através das notas dos discentes. Conforme aponta o autor, a mudança da função da avaliação, 
de diagnóstica para classificatória, não foi positiva. A avaliação deveria estabelecer um 'diagnóstico' do estágio em que se encontra o aluno, visando à tomada das decisões necessárias para que ele possa avançar no processo de aprendizagem. Contudo, sua atual função classificatória termina por estigmatizar o aluno, fato este ratificado pelos documentos, oficialmente emitidos pelas escolas, onde constam as notas.

Outro ponto fundamental relacionado à avaliação, destacado por Vasconcellos (1998), é a questão política que está atrelada a este processo. Conforme discute o autor, o processo educativo está atrelado ao poder e aos interesses das classes e, neste sentido, não há a possibilidade de estabelecimento de uma ação neutra por parte do educador. Quando ele se posiciona como neutro, na verdade está a favor dos interesses da classe dominante.

Devemos entender que este é um ponto culminante: o compromisso político dos profissionais que atuam na educação, em especial na educação profissional, haja vista que esta última lida com a tensão constante entre a formação de mão-de-obra qualificada, voltada às exigências do capital, e a formação emancipadora, que entende o trabalho - concebido e executado pelo ser humano - como condição central na vida das pessoas (Frigotto, 2002).

$\mathrm{Na}$ área da saúde do trabalhador, também é premente a formação de profissionais comprometidos com uma prática interdisciplinar e, para tanto, o constante diálogo com os diferentes campos do saber faz-se necessário. A adoção de formas democráticas de avaliação talvez possa estimular a reflexão e o próprio posicionamento do aluno ante as necessidades apontadas pelo mundo do trabalho e por nossa sociedade capitalista.

Talvez caiba repensar o nosso papel como educadores, perguntando-nos se atuamos para a transformação das desigualdades ou se apenas colaboramos para a perpetuação das injustiças sociais, a começar pela forma como as avaliações são elaboradas e transformadas em valores numéricos que comporão o currículo acadêmico do aluno, podendo excluir da sua vida a possibilidade de ascensão social.

\section{Notas}

${ }^{1}$ Professora pesquisadora da Escola Politécnica de Saúde Joaquim Venâncio, da Fundação Oswaldo Cruz (EPSJV/Fiocruz). Mestre em Saúde Pública pela Escola Nacional de Saúde Pública Sérgio Arouca (Ensp/Fiocruz).<marilda@fiocruz.br>

2 A coordenação deste módulo, em 2004, ficou sob responsabilidade dos professores Marilda Moreira e Sérgio Menezes, ambos do LAVSA/EPSJV, e Rosane Curi, do CESTEH/ENSP. 
${ }^{3}$ No módulo de Saúde do Trabalhador, os alunos organizam-se em grupos para desenvolver as monografias, apresentando-as à turma e à banca de pesquisadores (que fazem as ponderações sobre o estudo proposto e sobre a saúde do trabalhador). Além da apresentação oral e escrita da monografia, os grupos criam ainda um 'produto' relacionado ao objeto de estudo. Como exemplo de produtos confeccionados pelos discentes, podemos citar: músicas, fotonovelas, cartilhas, charges, peça de teatro, teatro de fantoches, maquetes etc.

4 Nas outras avaliações foram priorizados a música, o trabalho com argila e o conto.

5 Os integrantes da mesa foram os professores Blandina Marques, Raimunda Manga e Jorge Sandim. Por questões de segurança, optamos por manter o anonimato das duas senhoras vítimas do amianto. Recentemente, soubemos que uma delas veio a falecer.

6 Alguns dos alunos desta turma fizeram o ensino médio integrado ao curso técnico na EPSJV e tiveram a grande oportunidade de contar com o trabalho compromissado de profissionais que ministram as disciplinas Artes Plásticas, Música, Expressão Corporal e Teatro. Infelizmente, sabemos que esta não é a realidade vivida na maioria das escolas, sejam elas particulares ou públicas.

7 Além dos métodos que foram o objetivo central deste texto, a avaliação dos alunos foi composta por múltiplos elementos que visavam também ao fortalecimento do comprometimento dos alunos com os estudos teóricos, cabendo destacar: os fichamentos de artigos científicos; a exibição de vídeos, com posterior debate e produção de textos pelos alunos, em grupo ou individualmente; a auto-avaliação, que incluía uma justificativa do aluno sobre a nota que dera a si mesmo (e, neste ponto, cabe mencionar que discutíamos as dificuldades de se atribuir um valor numérico ao desempenho individual).

\section{Referências}

BOFF, Leonardo. 2002. A águia e a galinha: uma metáfora da condição humana. Petrópolis, RJ: Vozes.

CUÉLLAR, Javier P. de. 1997. Nossa diversidade criadora: relatório da comissão mundial de cultura e desenvolvimento. Campinas: Papirus; Brasília: Unesco.

D'ACRI, Vanda. 2003. Trabalho e saúde na indústria têxtil de amianto. São Paulo Perspectiva, v. 7, n. 2, p. 13-22.

FRIGOTTO, Gaudêncio. 2002. Trabalho, conhecimento, consciência e a educação do trabalhador: impasses teóricos e práticos. In: GOMEZ, Carlos M. et al. (org.). Trabalho e conhecimento: dilemas na educação do trabalhador. São Paulo: Cortez, p. 13-26.

GIDDENS, Anthony. 2000. Mundo em descontrole. Rio de Janeiro: Record.
HENDERSON, Joseph L. 2002. Os mitos antigos e o homem moderno. In: JUNG, Carl. G. (org.). O homem e seus símbolos. Rio de Janeiro: Nova Fronteira, p. 18103.

JUNG, Carl G. 2002. Chegando ao inconsciente. In: (org.). O homem e seus simbolos. Rio de Janeiro: Nova Fronteira, p. 104-157.

LÖWY, Michael. 1991. Ideologias e ciência social: elementos para uma análise marxista. São Paulo: Cortez.

LUCKESI, Cipriano Carlos. 2003. Avaliação da aprendizagem escolar. São Paulo: Cortez.

MORETTO, Vasco Pedro. 2004. Prova: um momento privilegiado de estudo, não um acerto de contas. Rio de Janeiro: DP\&A. 
PHILIPPINI, Angela. 2001. Cartografias da coragem: rotas em arte terapia. Rio de Janeiro: Pomar.

VASCONCELLOS, Celso dos S. 1998. Avaliação: concepção dialética-libertadora do processo de avaliação escolar. São Paulo: Libertad Centro de Formação e Assessoria Pedagógica

Recebido em 07/07/2006

Aprovado em 28/08/2006 
